\title{
La enseñanza de la Independencia Americana en Colombia y España 2009-2011 ${ }^{1}$
}

\author{
Teaching of the American Independence in Colombia and Spain \\ textbooks 2009-2011
}

\section{O Ensino da independência americana na Colômbia e na Espanha. Os textos escolares. 2009-2011}

\author{
Diana Elvira Soto Arango², Sandra Liliana Bernal Villate ${ }^{3}$, \\ William Pacheco Vargas ${ }^{4}$ \\ Universidad Pedagógica y Tecnológica de Colombia (Colombia) \\ Grupo de investigación HISUA
}

Yules Alejandro Espinosa ${ }^{5}$, Liliana Paternina Soto ${ }^{6}$ Universidad de Cundinamarca (Colombia) Grupo de investigación HISULA

\author{
Beatriz Perelló ${ }^{7}$ \\ Universidad de Alicante (España) \\ Grupo de investigación HISULA
}

1 Proyecto financiado por la Dirección de Investigaciones. UPTC. SGI.1130.2012-2013, con aprobación de la comisión de ética de la Universidad Pedagógica y Tecnológica de Colombia. El proyecto estuvo bajo la dirección de la Dra. Diana Elvira Soto Arango, Grupo de Investigación HISULA. Participaron en la investigación un equipo de profesores, jóvenes y semilleros de investigación de los grupos. HISULA Dr. William Pacheco, Mag. Sandra Bernal y del Grupo de investigación "La Ilustración en América Colonial". ILAC. el Dr. Jorge Tomás Uribe, Mag. Yaneth Ayala Soto, Jóvenes investigadoras Carolina Tovar, Eliana Tunarrosa, Carol Andrea Ruíz y el semillero Andrés González en la Universidad Pedagógica y Tecnológica de Colombia. Los profesores Mag. Alejandro Espinosa y Mag. Liliana Paternina de HISULA, actualmente docente en la Universidad de Cundinamarca. En España con el Dr. Fernando Betancourt Serna (HISULA), de la Universidad de Sevilla; el Dr. Justo Cuño (HISULA), de la Universidad Pablo de Olavide, España, en la Ciudad de Alicante con el Mag. José Antonio Perelló y la Mag. Beatriz Perelló (HISULA), de la Universidad de Alicante, con Diego Negrín Soto, Joven investigador, HISULA,Universidad Autónoma de Madrid, en ubicación y selección de textos escolares de sociales en España y análisis del sistema educativo en España. Este artículo es resultado del proyecto de investigación. La independencia Americana. Textos, enseñanza e imaginarios escolares SGI 1130, desarrollado por el grupo de investigación HISULA.

2 Docente titular de la Universidad Pedagógica y Tecnológica de Colombia. Doctorado en Filosofía y Ciencias de la Educación de la UNED, España, Postdoctorado del CSIC. Directora del Doctorado en Ciencias de la Educación RUDECOLOMBIA- CADE UPTC, es la Directora de los grupos de investigación Historia y Prospectiva de la Universidad Latinoamericana (HISULA), categoría A de Colciencias, y la Ilustración en América Colonial (ILAC), categoría A1 de Colciencias. Actualmente es integrante de la Sala de Educación CONACES Email diana.soto@uptc.edu.co

3 Docente ocasional de la Escuela de Ciencias Sociales de la Universidad Pedagógica y Tecnológica de Colombia, Doctoranda en Historia de América Latina de la universidad Pablo de Olavide - Sevilla - España e integrante del grupo de investigación HISULA. Email: sandra.bernal@uptc.edu.co

4 Docente ocasional de la Escuela de Ciencias Sociales de la Universidad Pedagógica y Tecnológica de Colombia, Doctor en Ciencias de la Educación. Actualmente es Director de la Escuela de Sociales e integrante del grupo de investigación HISULA. Email: william. pachecov@uptc.edu.co

5 Docente ocasional de la Universidad de Cundinamarca. Magíster en Estudios Políticos del Instituto de Estudios Políticos y Relaciones Internacionales "IEPRI", de la Universidad Nacional de Colombia. Director de Postgrados de la Universidad de Cundinamarca. Integrante del grupo de investigación HISULA. Email: yaespinosa@mail.unicundi.edu.co.

6 Magíster en Docencia de los Idiomas, actualmente es docente de la Universidad de Cundinamarca. Integrante del grupo de investigación HISULA. Email: lpaternina@hotmail.com

7 Licenciada en filología inglesa por la universidad de alicante y maestra en educación primaria por la universidad pontificia de Salamanca. máster en español e inglés para fines específicos. Colaboradora en didáctica de la lengua inglesa en varias universidades españolas. Email: perellobeatriz@gmail.com 
Recepción: 28/12/2014

Evaluación: 01/06/2015

Aceptación: 30/06/2015

Artículo de reflexión

\section{RESUMEN}

La investigación "La independencia americana en la enseñanza en Colombia y España 2009-2011", analizó las maneras cómo el tema de la independencia americana, desde la institución educativa y el aula escolar, (con los contenidos, mensajes, iconografía de los textos, guías y procesos de enseñanza aprendizaje) originó unos imaginarios sociales en los estudiantes de educación básica primaria y secundaria $(4,5,7$ y 8 grado), que asimilaron como una nueva identidad los ideales de la nación en la región cundiboyacense de Colombia, y en los grados 2 y 4 de la Secundaria Obligatoria (conocida como la ESO) de la Comunidad de Andalucía, España. Reconoce la historia de la educación dentro del contexto socioeducativo local, donde se delimitan los procesos de enseñanza-aprendizaje en instituciones escolares públicas y privadas que vehiculan contenidos, mensajes, representaciones sociales e iconografía sobre el tema de la independencia americana. Se pensó en los problemas relacionados con la producción de ideologías y de mentalidades, es decir, problemas propios del campo de las representaciones sociales. En la metodología, se utilizó la comparada con aproximación a la cartografía social. Se concluyó que los contextos socio-culturales de la institución y país conllevan a diferentes apreciaciones e interpretaciones sobre el tema de la independencia americana en los procesos de enseñanza-aprendizaje de Colombia y España.

Palabras clave: Revista Historia de la Educación Latinoamericana, enseñanza, Independencia americana, imaginarios, textos escolares.

\section{ABSTRACT}

This paper presents the findings of the investigation "Teaching of the American Independence in Colombia and Spain. 2009-2011", which analyzed how the issue of the American Independence from the school and the classroom (along with the contents, messages, iconography of texts, guides, and teaching and learning processes) originated some social imaginaries in students of basic primary education (4 and 5), who assimilate them towards a new identity in the imaginary of the nation in the Cundi-Boyacense region of Colombia and in 2 ESO and 4 High School of the Province of Andalusia, Spain. It recognizes the history of education within the local socio- educational context where teaching and learning processes are delimited in public and private educational institutions that carry contents, messages, social imaginaries and iconography on the subject of the American Independence. It presents a reflection on problems related to the production of ideologies, imaginaries and mentalities. That is, problems belonging 
to the field of social representations. It was used the compared methodology approaching the social mapping, from the spatial imagination. It was concluded that the socio-cultural contexts of the institution and the country lead to different insights and imaginaries on the subject of the American independence in the teaching and learning processes of Colombia and Spain.

Key words: Journal History of Latin American Education, teaching, American Independence, imaginaries, textbooks.

\section{RESUMO}

Se apresenta o resultado da pesquisa "A independência americana no ensino na Colômbia e na Espanha 2009-2011", que analisou as maneiras como o tema da independência americana, a partir da instituiçãoeducativa e da aula escolar (com os conteúdos, mensagens, iconografia dos textos, guias e processos de ensinoaprendizagem) originou uns imaginários sociais nos estudantes de educação básica primária (4 e 5), que assimilam na direção de uma nova identidade no imaginário da nação na região cundi-boyacense da Colômbia, e em 2 ESO (Ensino Secundário Obrigatório) e 4 Bacharelado na província de Andalucía, Espanha. Reconhece a história da educação dentro do contexto socioeducativo local, de onde se delimitam os processos de ensinoaprendizagem em instituições escolares públicas e privadas que veiculam conteúdos, mensagens, imaginários sociais e iconografia sobre o tema da independência americana. Se pensou os problemas relacionados com a produção de ideologias, de imaginários e de mentalidades. Isto é, problemas próprios do campo das representações sociais. $\mathrm{Na}$ metodologia, se utilizou a comparada com aproximação à cartografia social a partir da imaginação espacial. Concluiuse que os contextos socioculturais da instituição e do país levam a diferentes apreciações e imaginários sobre o tema da independência americana nos processos de ensino-aprendizagem da Colômbia e da Espanha.

Palavras-chave: Revista História da Educação Latino-americana, Ensino, Independência americana, imaginários, textos escolares.

\section{INTRODUCCIÓN}

El proyecto analizó las maneras cómo el tema de la independencia americana, desde el aula escolar, (con los contenidos, mensajes, iconografía de los textos, guías y procesos de enseñanza-aprendizaje) originó unos imaginarios sociales en los estudiantes de educación básica primaria ( 4 y 5 grado) y secundaria ( 7 y 8$)$ que asimilan como una nueva identidad en el imaginario de la nación en la región cundi-boyacense de Colombia, y en España en 2 y 4 de la Secundaria Obligatoria (conocida como la ESO) de la Comunidad de Andalucía ${ }^{8}$. Por lo

$8 \quad$ Véase un estudio sobre la identidad andaluza donde indican que tiene una diversidad histórica desde los romanos, el ad andaluz unidos más adelante por la figura de Blas Infante como padre de la patria andaluza. Juan Luis Rubio Mayoral y Guadalupe Trigueros Gordillo "La formación de la conciencia andaluza y el ser andaluz en los manuales escolares", en Ciudadanía e identidades en los manuales escolares (1970-2012). (Edt.). Miguel Beas (Sevilla - España: Diada Editorial, 2013), 154-155 
tanto, el hilo conductor se estableció, en el estudio, a través del imaginario sobre la "independencia americana" que se ha formado en los estudiantes de primaria y secundaria en Colombia y España y nos planteamos la siguiente pregunta general ¿Cuáles son los imaginarios de los estudiantes, sobre la independencia americana, que se han vehiculado a través de las aulas de clase en España y Colombia en el período de 2009, 2010, 2011?

Se estableció el marco teórico desde la historia social de la educación, de las mentalidades ${ }^{9}$ y los imaginarios ${ }^{10}$, dentro del contexto socio-educativo local, donde se delimitan los procesos de enseñanza aprendizaje en instituciones escolares públicas y privadas de Colombia (zona Cundi-boyacense ${ }^{11}$ ) y España (Comunidad de Andalucía), que vehiculan contenidos, mensajes, imaginarios sociales e iconografía sobre el tema de la independencia americana. De esta manera, se analizaron los problemas relacionados con la producción de ideologías, de imaginarios y de mentalidades. Es decir, problemas propios del campo de las representaciones sociales, como fue el imaginario escolar sobre la independencia. Desde estos componentes de análisis se pudo reconocer el plan de estudios y proceso de enseñanza-aprendizaje en el tema de la independencia americana.

La metodología usada fue la comparada con aproximación a la cartografía social $^{12}$ desde los imaginarios ${ }^{13}$ para permitir el diálogo entre las cuatro hipótesis $^{14}$. De esta manera, establecimos el análisis por el método de la similitud y la diferencia de las variables e indicadores que guiaron, desde las hipótesis, la investigación para establecer el mapa conceptual. Las estrategias se sustentaron en las encuestas y entrevistas, aprobadas por la comisión de ética de la Universidad Pedagógica y Tecnológica de Colombia. La legislación ${ }^{15}$

9 Marc Bloch. Historia e historiadores. (Madrid: Editorial Akal, 1999), 245 a 253. Julián Casanova. La historia social y los historiadores. (Barcelona: Edt. Crítica. Leer: Todo el libro. Biblioteca. Dubby, 1997). Georges. Historia social e ideología de la sociedad. (Barcelona: Anagrama, 1976). Joseph Fontana. La historia de los hombres del siglo XX. (Barcelona: Editorial Crítica, 2002). Joseph Fontana y otros. Hacia una nueva Historia. Prólogo de Alberto Manuel Prieto Arciniega. (Madrid: Akal Editor, 1976). Michelle Vovelle. Ideologías y mentalidades. (Barcelona: Editorial Crítica,1987). Gabriel Almond y Sidney, Verba. The Civic Culture; Political Attitudes and Democracy in Five Nations, (Princeton, NJ: Princeton University Press, 1963). César Augusto Ayala Diago (editor). La historia política hoy. Sus métodos $y$ las ciencias sociales, (Bogotá: Universidad Nacional de Colombia, 2004). Samaran, C. L'historie et ses méthodes. (París: Gallimard, 1961). Michelle Vovelle): Ideologías y mentalidades. (Barcelona: Editorial Crítica, 1887).

10 El concepto de "imaginario", constituye una "categoría clave en la interpretación de la comunicación en la sociedad moderna como producción de creencias e imágenes colectivas". Véase en, Benedict Anderson. Imagened Communities, Verso, (London, 1983). Cornelius Castoriadis. La institución imaginaria de la Sociedad, (Tusquets: Editores, Buenos Aires, 1975).------ (1990) El mundo Fragmentado, (Colección Caronte Ensayos, Montevideo, 1997). Gilbert Durand. Les structures antrhopologiques de l'imaginaire: introduction á l'archétypologie générale, (Borda: París, 1960), Gilbert Durand 1969. Stuart Hall, Paul du Gay (comp.). Cuestiones de identidad cultural, Amorrortu, (Buenos Aires, 2003). Armando Mattelart. La invención de la comunicación, (Barcelona. Bosch, 1995), Celso Sánchez Capdequí. Imaginación y sociedad: una hermenéutica. Creativa de la cultura, (Madrid: Tecno-Universidad Pública de Navarra,1999)

11 El área de estudio abarcó la zona central de Colombia comprendida entre la cordillera occidental de Los Andes y zona alta del valle del Río Grande de la Magdalena, que abarca los departamentos de Boyacá y Cundinamarca.

12 Se utiliza porque permite el análisis de narraciones, preguntas abiertas, entrevistas. Lo sustentamos en las teorías de Paulston, R. Mapping comparative education after postmodernity, (Comparative Education Review, 43, 1999), 438-463.

13 Paulston, R. Imagining comparative education: past, present, future, Compare Review, 30 (2000), 354-359.

14 Lo utilizamos por permitir el mapa cognitivo que nos aproxima al análisis de los imaginarios. Que en palabras de Paulston indica que en la educación comparada establece "el mapero heurístico de las interrelaciones eclécticas del conocimiento" Paulston, R. Mapping discourse in comparative education text, Compare Review 23, (1993), 106. Se incluyó 4 hipótesis dos desde la diferencia y dos por la similitud.

15 La Constitución Política de Colombia se publicó en la Gaceta Constitucional Número 127 del día jueves 10 de octubre de 1991, y estableció un nuevo marco jurídico a la educación en Colombia. La Ley 115 General de la Educación del 8 febrero de 1994. Decreto 
dio soporte a la política educativa y los planes curriculares. Las guías, textos y manuales escolares se retomaron en su análisis de otros estudios que hemos realizado sobre este tema ${ }^{16}$.

Estas encuestas y entrevistas, guiaron el análisis, desde la retrospectiva (cohorte histórica) en los años 2009 (año anterior a la celebración del bicentenario) y 2010 (año de la celebración) y prospectiva con la cohorte del 2011(año posterior a la celebración), en épocas y contextos político-educativos que configuran procesos de identidad socio-cultural de estudiantes colombianos y españoles. La población de estudiantes fue seleccionada aleatoriamente en cada colegio y con una muestra del $10 \%$ en cada curso donde se realizó la encuesta ${ }^{17}$. Se eligieron únicamente profesores que impartían teoría sobre la independencia americana en la asignatura de sociales en cursos de educación secundaria.

Esta muestra, se determinó, desdeel mapa conceptual, sustentado en las cuatro hipótesis (dos de similitud y dos de diferencia) y dos variables independientes (país y lugar) y tres dependientes (institución, grado y género).

Se concluye, que el tema de la independencia americana que se imparte, en la institución escolar, desde el aula de clase, en los procesos de enseñanzaaprendizaje de Colombia y España, presenta imaginarios diferentes que varían según los contextos socio-culturales de la institución y país. De esta manera, conlleva a diferentes apreciaciones que al originar unos imaginarios sociales no permean los valores de la sociedad del conocimiento que deben marcar a la institución escolar.

\section{La muestra del estudio determinada por el imaginario histórico}

En primera instancia, el objeto del estudio se centró en el proceso de enseñanza - aprendizaje del tema la independencia, en el curso de sociales en España y Colombia. El proceso se estableció partiendo de la hipótesis de la utilización por parte del profesor del "paradigma moderno donde el acto pedagógico de este mediador (educador), se orienta desde el pensamiento creativo a conectar el conocimiento de la independencia con el cómo se enseña, sin reducir el discurso a la instrumentalización"18 de la guía o el texto escolar, para llevar al estudiante a un pensamiento crítico sobre este hecho histórico. Por lo tanto, nos centramos en analizar ese proceso pedagógico desde la mirada del componente ideológico, que fue correlacionado entre el texto, las guías didácticas con las encuestas y

1860 de 1994. Aspectos pedagógicos. Resolución 2343 del 5 junio de 1996 (logros curriculares). De 1995 al 2005, se aplica el Plan Decenal de educación que se rigió por la Ley 115 del 8 de febrero 1994.

16 Diana Soto Arango. "La independencia americana en los textos escolares en Colombia", en Ed. Rosa M. Bestani... [et.al.]. - Textos, autores y bibliotecas. 190 años de la Biblioteca Mayor de la UNC /. (Córdoba: Universidad Nacional de Córdoba, Argentina. Biblioteca Mayor, 2011), 457-469.

$17 \mathrm{Al}$ ser una investigación cualitativa la encuesta no se mira desde la cantidad sino con la metodología del grupo focal determinado por el curso donde se impartía el tema de la independencia americana.

18 Diana Soto Arango. "Ciencias de la educación y pedagogía. Un debate inconcluso en las Facultades de Educación en Colombia" en Revista Ambiente Educação, (Brasil) Revista digital http://www.cidadesp.edu.br/old/revista_educacao/index.html 
entrevistas realizadas a profesores y estudiantes, donde se ha impartió el tema de la independencia americana en el año 2009, un año antes del bicentenario, en el 2010 año de la celebración y luego en el 2011, en la prospectiva, para establecer la diferencia por el impacto que se había dado a esta celebración en España y Colombia.

Desde el anterior argumento, como hemos indicado, el marco teórico que orientó la investigación lo reconocemos desde la historia social de la educación dentro del contexto socio-educativo local, donde se delimitan los procesos de enseñanza-aprendizaje en instituciones escolares públicas y privadas que vehiculan contenidos, mensajes, imaginarios sociales e iconografía sobre el tema de la independencia americana.

La metodología de la educación comparada, permitió establecer el mapa conceptual desde la cartografía social centrada en los imaginarios. Es así como la población definida y utilizando la técnica de sustento en la hipótesis para llevar a cabo este mapa conceptual se establecieron las dos variables independientes correlacionadas cada una con tres variables dependientes.

Por lo tanto, el mapa conceptual lo centramos en las siguientes hipótesis de trabajo: Hipótesis 1. (Similitud): Los países y los lugares seleccionados tienen un mayor acercamiento, en el contexto institucional, al tema de la independencia americana. Hipótesis 2. (Diferencia). Los planes de estudio con los contenidos sobre el tema de la independencia americana presentan diferencias conceptuales en los dos países seleccionados. Hipótesis 3. (Similitud). En los dos países con sus lugares de estudio intervinieron, como institución educativa, en las actividades extraescolares de reconocimiento o celebración del hecho histórico del Bicentenario de la independencia americana. Hipótesis 4. (Diferencia). El proceso de enseñanza con los medios educativos, en el tema de la independencia, presenta diferencias por país, lugar y tipo de institución.

Las variables independientes fueron: Primero, el País (Colombia y España) y lugares donde se consideró que las poblaciones tenían un mayor acercamiento al tema de la independencia. La segunda variable independiente en relación a los lugares, en España, se seleccionó la comunidad de Andalucía con tres poblaciones: Sevilla, Santa María, Huelva y en Alicante una institución para el análisis de la Biblioteca escolar. Se aplicaron encuestas y entrevistas en los años 2010 y 2011. Destacamos, la ciudad de Sevilla, puerto fluvial del Guadalquivir, caracterizada en el imaginario por la acogida aún hoy en día, a los inmigrantes de América, pero en especial, con un gran componente histórico al ser la sede del Archivo General de Indias. Por todo lo anterior, consideramos que estos lugares con sus instituciones educativas nos podrían dar una visión panorámica del imaginario sobre la independencia americana.

En el caso colombiano, se seleccionaron los lugares por la mayor vinculación al tema de la independencia de la Nueva Granada. Los indicadores se establecieron 
por el hecho, de que en estos lugares se llevaron a cabo sucesos de transcendencia histórica, como la realización de batallas, por el paso del ejército libertador y por la influencia de la Expedición Botánica como es el caso de Municipio de Fusagasugá para Colombia.

En las variables dependientes, la primera, es la referente a la institución pública y privada con el indicador de formación que impartía la institución educativa: académico, agrícola, normalista, técnico; la segunda, la centramos en el grado escolar donde se enseñaba el tema de la independencia, que para el caso colombiano fueron: 4, 5, 7, y 8 grado. En el caso español: 2 y 4 de la ESO. La tercera variable dependiente, fue la referente a las respuestas de los estudiantes, analizada por género, excepto donde los colegios privados fueran masculinos o femeninos, según el caso, en relación al imaginario sobre la independencia americana, con las causas, consecuencias y los líderes.

Hay que decir, que analizamos una variable de tipo transversal referente al proceso de enseñanza y medios educativos, que se compararon con las entrevistas a los profesores, estudiantes, legislación, planes de estudios, textos, guías.

Debemos indicar en este sentido, que la educación en España se encuentra reglamentada por la Ley Orgánica de Educación 2, del 3 de mayo de 2006. En el sistema educativo español se distinguen estos niveles educativos. El primero, la educación infantil (entre los $3^{19}$ y los 6 años), de carácter no obligatorio, aunque los colegios públicos reciben estudiantes a partir de los 3 años. Segundo, la educación primaria comprende 6 cursos (regularmente edades entre los 6 y los 12 años), es obligatoria y por lo tanto gratuita en instituciones públicas. En algunas comunidades se otorgan los libros o ayuda para la compra de los mismos como es el caso de la Comunidad Autónoma de Andalucía. Tercero, la Educación Secundaria obligatoria, ESO, 4 cursos, entre los 12 y los 16 años aproximadamente. Nosotros aplicamos encuestas en 2 y 4 de la ESO. Cuarto, la educación secundaria ${ }^{20}$, después de haber cursado al ESO que presenta 5 tipos de educación diferente. El bachillerato (2 cursos) con edades de 16 y 18 años y prepara para el ingreso a la Universidad; la formación profesional de grado medio; las enseñanzas profesionales de artes plásticas y diseño de grado medio, y las enseñanzas deportivas de grado medio. En nuestro caso, nos interesa destacar la ESO donde aplicamos las encuestas. El Ministerio de Educación Nacional de España define la Educación Secundaria Obligatoria - ESO como [...] una etapa educativa obligatoria y gratuita que completa la educación básica. Consta de cuatro cursos académicos que se realizarán ordinariamente entre los 12 y los 16 años de edad. La ESO, se organiza de acuerdo con los principios de educación común y de atención a la diversidad del alumnado, presta especial atención

19 La educación infantil comienza a los 3 años. Antes de los 3 hay guarderías no financiadas por el estado.

20 Ministerio de Educación y Ciencia. Boletín Oficial del Estado Español, Real Decreto 1467 de 2 de noviembre, por el cual se estructura el bachillerato y se fijan sus enseñanzas mínimas, número 266 (2007):45381-45477. Se debe indicar que en el año 2012 la LOE presentó variaciones pero los niveles se conservan. Nosotros en este estudio nos sustentamos en la de 2007, vigente en la fecha de aplicación de las entrevistas y encuestas. 
a la orientación educativa y profesional. La Educación Superior Obligatoria - ESO tiene como finalidad lograr que todos adquieran los elementos básicos de la cultura: humanísticos, artísticos, científicos y tecnológicos, desarrollar y consolidar hábitos de estudio y de trabajo, preparar para la incorporación a estudios posteriores y para su inserción laboral, formar a todos para el ejercicio de sus derechos y obligaciones en la vida como ciudadanos ${ }^{21}$. Igualmente, para la aplicación de las encuestas se tuvo en cuenta el Real Decreto 1631 de 29 de diciembre de 2006, en donde se establecen las enseñanzas mínimas correspondientes a la Educación Superior Obligatoria - ESO ${ }^{22}$. Teniendo en cuenta lo anterior, se determinó los cursos 2 y 4 de la ESO donde se imparte el tema de la independencia americana.

En Colombia, el sistema educativo actual se sustenta en la Ley 115 del 8 de febrero de $1994^{23}$, por medio de la cual se expide la Ley General de Educación, vigente en la actualidad ${ }^{24}$. La Ley 115 presenta 11 títulos y 227 artículos. En esta Legislación destacamos que recoge la política pública de la Constitución Colombiana del año 1991. La citada Ley en su Artículo 10 define la educación formal ${ }^{25}$, y el Artículo 11 establece los niveles de educación formal que se organiza en tres (3) niveles. a). El pre-escolar que comprenderá mínimo un grado obligatorio. b). La educación básica con una duración de 9 grados que se desarrollará o desarrolla en dos ciclos: La educación básica primaria de cinco (5) grados y la educación básica secundaria de cuatro (4) grados, y c). La educación media con una duración de dos (2) grados. Asimismo, establece en el Artículo 23 en el Numeral 2, las áreas obligatorias fundamentales donde se ubica en el numeral 2 "Ciencias sociales, historia, geografía, constitución política y democracia". Localizamos que el tema de la independencia americana se encuentra en los planes de estudio de la educación primaria y secundaria.

En definitiva, los niveles educativos en España se dividen en cuatro, siendo obligatorias la primaria con 6 cursos, y la secundaria con 4 cursos para un total de 10 cursos. Por el contrario, en Colombia, se establece un nivel de pre-escolar obligatorio un curso y luego lo que se denomina básica primaria y secundaria tiene 9 cursos obligatorios. La Educación Media en Colombia presenta 2 cursos, y el Bachillerato en España igualmente 2 cursos. El tema de la independencia americana se imparte en Colombia en la primaria y secundaria en los grados 4, 5, 7 y 8. En España, en la secundaria (ESO) en el 2 y 4 curso.

21 Ministerio de Educación Nacional de España. “Enseñanza Superior Obligatoria”. [en línea]. [España]. http://www.mec.es/educacion/ que-estudiar/educacion-secundaria-obligatoria.html.(consultada en febrero de 2011)

22 Ministerio de Educación y Ciencia. Boletín Oficial del Estado Español, Real Decreto 1631 de 29 de diciembre, por el cual se establecen las enseñanzas mínimas correspondientes a la Educación Secundaria Obligatoria, número 5, (2007): 667-773.

23 Esta Ley la expide el Congreso de la República de Colombia. En el Artículo 5 define los fines de la educación según el artículo 67 de la Constitución Nacional.

24 En mayo de 2015 se expidió el Decreto 1075 que unifica todas las leyes y decretos en educación, pero no establece cambios.

25 Ley 115 de febrero 8 de 1994. Artículo 10. Se entiende por educación formal aquella que se imparte en establecimientos educativos aprobados, en una secuencia regular de ciclos lectivos, con sujeción a pautas curriculares progresivas y conducentes a grados y títulos. 
En las estrategias de la investigación, se sustentaron en las encuestas aplicadas a los estudiantes seleccionados de manera aleatoria, en cada grado, sobre un mínimo del $10 \%$ y entrevistas realizadas a los profesores de sociales donde se impartía el tema de la independencia. Como hemos indicado, las encuestas y entrevistas pasaron la evaluación del Comité de Ética.

En concreto, en marzo del año 2010 en la Comunidad de Andalucía, España, se aplicaron un total de 46 encuestas en 5 colegios, de estos los tres colegios privados fueron: Colegio Guadalete en el Puerto de Santa María (grado 4 de la ESO); Colegio Entrepinos (grado 4 de la ESO) y Colegio Tierra Llana en Huelva (grado 4 de la ESO solo femenino). Los dos colegios públicos, ubicados en la ciudad de Sevilla: Instituto de Educación Superior Gustavo Adolfo Becquer (grado 2 de la ESO), (Grupo Attendis) Instituto de Educación Superior Santa Aurelia (grado 4 de la ESO), (Grupo Attendis). Se realizaron encuestas a 23 estudiantes de estos, 11 del género masculino y 12 del género femenino y 23 a estudiantes de tres instituciones privadas (Huelva 2, Santa María 1) de las cuales 17 correspondían al género masculino y 6 al género femenino. En febrero del año 2011, nuevamente en España, se aplicaron en Sevilla un total de 20 encuestas, de las cuales 10 estudiantes pertenecen a una institución pública: el Instituto de Educación Superior Gustavo Adolfo Becquer (grado 2 de la ESO) (5 del género masculino y 5 a género femenino) y 10 a estudiantes de la institución privada Colegio Entrepinos (grado 4 de la ESO) (10 del género masculino). De esta manera, en total, en los dos años se aplicaron entre el 2010 y 2011: 66 encuestas a estudiantes de las 3 instituciones públicas y las 4 privadas. Igualmente, 11 entrevistas a profesores. Reiteramos que nuestra investigación no tenía ninguna pretensión de realizar un análisis estadístico. Lo que nos interesaba, era el análisis cualitativo sustentado en el mapeo de las cuatro hipótesis, referentes al imaginario de la independencia americana.

Por otra parte, en Colombia el estudio se inició en el año 2009, un año antes de celebrarse el bicentenario de la Independencia en este país, con el criterio de conocer cómo se enseñaba el tema de la independencia y que imaginarios se tenían sobre el mismo.

La aplicación de las encuestas en Colombia se realizó en 9 lugares; dos de estos correspondían a sitios que tuvieron en su suelo las batallas que dieron origen a la libertad de la Nueva Granada, entre ellas la del Pantano de Vargas (25 de julio de 1819) y la del Puente de Boyacá (7 de agosto de 1819).

Ental sentido, cada lugar tiene un referentehistórico. Por tal razón, se seleccionó la ciudad de Fusagasugá, por considerarse uno de los sitios privilegiados de la Expedición Botánica a finales del siglo XVIII y donde estuvo radicado el Subdirector Francisco Antonio $\mathrm{Zea}^{26}$. Además, hay que decir, que esta ciudad fue

26 Zea fue también el primer vice-presidente de la nueva República neogranadina en 1819. Véase en, Diana Soto Arango. Francisco Antonio Zea un criollo Ilustrado. Madrid, Colección Thesauros. (RUDECOLOMBIA, CONUEP, Instituto Colombiano de Cultura Hispánica, Consejo Superior de Investigaciones Científicas, COLCIENCIAS, Ediciones Doce Calles, 2000), 31-47. 
fundada en 1529 como caserío indígena y en 1776 como pueblo de blancos. En el momento del estudio, la población ascendía a los 110 mil habitantes ${ }^{27}$, siendo la capital de la Provincia del Sumapaz y un importante núcleo de desarrollo en el sur del Departamento de Cundinamarca ${ }^{28}$.

Aún hay otra distinción, y es el hecho de nuestro propósito de localizar los imaginarios frente al tema de la independencia americana en el antes y el después de la celebración. Es así como las primeras encuestas fueron aplicadas en el mes de octubre de 2009, en la ciudad de Fusagasugá, cuando ya se había impartido el tema de la independencia americana ${ }^{29}$. Allí, se aplicaron encuestas a 88 niños y 82 niñas entre los 9 y 14 años y se entrevistaron 11 profesores de sociales, en 9 colegios: seis de carácter oficial y tres privados; en los grados cuarto, quinto, séptimo y octavo. Es relevante indicar que el propósito de aplicar las encuestas en colegios públicos y privados se realizó con el objeto de establecer las diferencias en los conocimientos, imaginarios, y asimismo, analizar las respuestas por categoría de género: masculino-femenino y las respuestas según el grado en primaria y secundaria sobre el tema independencia americana. Pero, además se tenía otro propósito como era el de validar la prueba de las encuestas y los indicadores de la entrevista. La segunda aplicación, correspondió al año 2011 en la misma ciudad de Fusagasugá. En esta ocasión, se aplicaron un total de 179 encuestas en los cursos 5, 6, 8 y 9. Es decir, en cursos donde el año anterior habían tratado en la clase de sociales, el tema de la independencia. Hay que destacar, que de estos 99 estudiantes de las instituciones públicas (41 a género masculino y 58 a género femenino), y 80 estudiantes de instituciones privadas (35 a género masculino y 45 a género femenino) entre los 9 y 14 años nos permitieron tener una visión más exacta del antes y el después de la celebración de la independencia, encontrándose elementos diferenciales por la influencia de los medios de comunicación y en especial, por una telenovela llamada La Pola por la heroína Policarpa Salavarrieta. Asimismo, la entrevista realizada a los 10 profesores de sociales, en 8 instituciones educativas, de las cuales 4 eran públicas y 4 privadas, presentaron que sí se les había permeado el concepto e imaginario en esta temática a través de la política del Ministerio de Educación Nacional y, especialmente, por los medios de comunicación. En total, en la población de Fusagasugá, en las fechas de octubre de 2009 y mayo de 2011, se desarrolló la investigación en 17 colegios, 10 de carácter oficial y 7 privados, aplicándose 349 encuestas a estudiantes de los grados cuarto, quinto, séptimo, octavo, y noveno, a niños y niñas entre los 9 y 16 años. Además, se entrevistaron 21 profesores de sociales en los diferentes colegios visitados, indagando sobre los temas y metodologías utilizadas por ellos para enseñar el tema de la independencia.

27 Según el DANE en el año 2005 tenía 107.259 habitantes. (Censo DANE 2005).

28 Es uno de los 116 municipios del departamento de Cundinamarca en la región central de Colombia. Conocido como "Ciudad Jardín de Colombia” también llamado "Tierra Grata”.

29 Debemos indicar que las encuestas aplicadas en la ciudad de Fusagasugá en el año 2009 se realizaron para validar el instrumento. Colaboraron en la aplicación y análisis el Lic. Edgard Javier Bautista Pineda y la Mag. Liliana Paternina Soto. 
Sin embargo, hay que mencionar, que de igual manera se analizaron los textos y guías empleados por los docentes como medio de enseñanza. Se escogió también la población de Pasca, allí se aplicaron en la Normal Superior (pública), 40 encuestas a estudiantes y entrevistas a 2 profesores en el año 2011.

En el año 2011 se aplicaron en Colombia, en 7 lugares de Boyacá, que se caracterizaron por ser lugares del recorrido del ejército libertador de Bolívar. En estas ciudades y lugares se aplicaron las encuestas en el curso superior donde se había impartido el tema de la independencia. Es decir, los estudiantes habían recibido el tema el año anterior, fecha en la cual el Ministerio de Educación Nacional de Colombia celebró la independencia con gran visibilidad en medios de comunicación y como hemos indicado se presentó una telenovela de gran impacto nacional sobre la heroína La Pola. Los sitios seleccionados del año 2011, en el departamento de Boyacá, fueron:

La ciudad de Paipa que significa $\mathrm{Pa}$ en lengua muisca, es varón, benefactor, señor o padre. Dos veces Pa debía significar patrón, gran señor o protector. Paipa urbana, data del 19 de febrero de 1602, declarada por Luis Enríquez como un centro de adoctrinamiento en el lugar donde hoy se ubica la Plaza principal. Desde sus inicios Paipa era el lugar predilecto para el veraneo, gracias a su clima y por supuesto a sus aguas termales. Paipa fue lugar de paso de Bolívar y de Rondón luego de la Batalla del Pantano de Vargas a $10 \mathrm{Km}$. de esta ciudad. Las instituciones educativas oficiales en las que se aplicó la encuesta en 5, 6, 8 y 9 grado fueron: Instituto Técnico Agrícola de Paipa ${ }^{30}$; La Técnica Tomás Vásquez Rodríguez (Municipal)31; Armando Solano, (institución departamental); El Rosario (mixto, bachillerato académico) ${ }^{32}$. Y, las instituciones privadas de: Fray Arturo Ayala, Colegio Miguel Jiménez López y la Concentración Pablo Solano. En el Pantano de Vargas, el Colegio Juan José Rondón (oficial) fue el elegido. Debemos indicar que esta institución presentó un proyecto educativo en el 2010, en el Foro Municipal y Departamental, "Aprendiendo con el Bicentenario". Visionando el Bicentenario 2019, que busca una transformación social y educativa en todos los municipios (Cerinza a Ventaquemada) que participaron por los caminos en la ruta en la campaña libertadora, publicado en el primer periódico virtual escolar de Boyacá, denominado "El Picacho".

En Socha fue elegida otra institución, este municipio se localiza a $117 \mathrm{~km}$. de Tunja, la capital del Departamento. La palabra Socha significa: “Tierra del Sol y la Luna" y no deja de ser curioso que de los 10 barrios de esta población, 5 tienen

30 Se inicia como Escuela Normal Agrícola en Duitama (Hoy Instituto Técnico Rafael Reyes), mediante el Decreto del Ministerio de Educación Nacional (MEN), No. 489 del 12 de octubre de 1949. Con la creación de la Universidad Pedagógica de Colombia en 1953, se anexa a esta institución con sede en Paipa en 1954, en el casco urbano, en 1961 se traslada a la hacienda el Salitre hoy Foyerd de Charité, en unas instalaciones ubicadas en la vereda del Salitre, donde posee 230 hectáreas, a 8 Kilómetros de la ciudad. Mediante la Ley 73 del 14 de diciembre de 1963, dejó de depender de la Universidad y se reintegró al MEN.

31 Forma bachilleres técnicos con especialidad en turismo, diurna; bachilleres académicos jornada nocturna, con sentido de idoneidad y desarrollo de competencias laborales, para que sean capaces de asumir la búsqueda de soluciones a las necesidades individuales, sociales, ambientales y de la comunidad.

32 El Bachillerato presenta profundización en ciencias naturales y educación ambiental, educación artística y cultural, básica secundaria, básica primaria y preescolar. El establecimiento es uno de los más tradicionales del municipio e inició actividades en 1930. 
nombres que los relacionan con la independencia (20 de julio, Centenario, Los Libertadores, Simón Bolívar y 7 de Agosto). La institución oficial seleccionada fue la Escuela Normal, creada en 1953.

Entre Paipa, Socha y Pantano de Vargas, se aplicaron un total de 127 encuestas. De este gran total, 75 estudiantes corresponden a las 6 instituciones públicas (37 de género masculino y 38 de género femenino) y 52 estudiantes de 3 instituciones privadas (26 del género masculino y 26 del género femenino).

En este mismo departamento, se aplicaron encuestas a estudiantes y entrevistas a profesores, en zonas ubicadas en el norte de Boyacá. La población de Güicán, está localizada a $255 \mathrm{~km}$. de Tunja. Lo relevante es que el 81\% del territorio hace parte del Parque Nacional Natural El Cocuy. El origen de la población se localiza en la tribu chibcha y el nombre de Güicán en lengua aborigen significa "en el cercado de la esposa". Esta población fue una de las primeras en declarar la independencia de España el 24 de febrero de 1814. La encuesta se aplicó en la Escuela Normal Superior Nuestra Señora del Rosario de Güicán a 20 estudiantes, de estos 10 niños y 10 niñas, actividad llevada a cabo en el mes de marzo de 2011. La otra población cercana a Güicán es la del Cocuy, denominada como la "Ciudad del Nevado", su nombre da origen al parque natural de El Cocuy y a la Sierra Nevada del Cocuy. En esta población se aplicaron en el colegio público, José Santos Gutiérrez, 20 encuestas a 10 niños y 10 niñas, en la misma fecha. Es necesario mencionar, que en cada colegio se entrevistó al profesor encargado del área de sociales ${ }^{33}$.

Tunja, la capital del departamento de Boyacá, corresponde a la Fundación Hispánica del 6 de agosto de 1539, por el Capitán Gonzalo Suárez Rendón. Se levantó la villa sobre las bases urbanas de la HUNZA indígena. En esta capital, se aplicaron 127 encuestas a 4 instituciones públicas (INEM, Emiliani, Boyacá, Normal Superior, y a tres instituciones privadas: Colegio Cooperativo Cooservicios, El Salesiano y Los Ángeles.

Pero de especial relevancia, fueron las dos aplicaciones realizadas en los lugares que corresponden al ícono de la independencia y donde se derrotó al ejército realista español. Estos fueron el Pantano de Vargas a $10 \mathrm{Km}$. de la ciudad de Paipa, que ya relacionamos. Y, en el Puente de Boyacá ${ }^{34}$, lugar emblemático para los colombianos por considerarse que allí se dio la batalla final dando origen a la independencia de la Nueva Granada, el 7 de agosto de 1819. Este lugar está localizado a $15 \mathrm{Km}$. de la ciudad de Tunja. En este municipio se entrevistaron en el Colegio Panamericano (de orden público) a 10 estudiantes, junto con el profesor de sociales.

33 Las instituciones fueron: Escuela Normal Superior Nuestra Señora del Rosario de Güicán de La Sierra y el Colegio José Santos Gutiérrez El Cocuy. Fecha de aplicación de encuesta: 15 y 18 de marzo de 2011 en el grado quinto por Eliana Tunarrosa, joven investigadora del Grupo de investigación "La Ilustración en América Colonial”. ILAC. Profesores: Luz Mery Mora (Güicán) y Javier Eduardo Buitrago Mora (El Cocuy).

Donde se llevó a cabo la Batalla de Boyacá el 7 de agosto de 1810. 
En definitiva, la muestra se ubicó en 12 lugares: nueve en Colombia y tres en España, adicionalmente, se ubicó un colegio adicional, solo para entrevistar al rector y hacer el análisis de la biblioteca escolar. Se seleccionaron un total de 45 instituciones, de las cuales se localizan 28 públicas $^{35}$ y 17 privadas. Las encuestas se aplicaron a 699 estudiantes: 357 niños y 342 niñas. El período del estudio se estableció entre los años 2009, 2010 y 2011. En cada institución se entrevistó mínimo a un profesor de la cátedra de sociales, que impartía el tema de la independencia, para un total de 51 docentes.

Lo relevante de la aplicación de estas encuestas, fue el hecho de poder conocer los imaginarios sobre la independencia, que en el caso de Colombia varió sustancialmente luego de la celebración del año 2010. Especialmente, localizamos una fuerte influencia de los medios de comunicación. En el caso español, la independencia americana presentó variaciones en el imaginario de los estudiantes no por la celebración del bicentenario, sino por el hecho de haber recibido o no el tema en el aula de clase. El siguiente apartado dará cuenta de estos imaginarios

\section{Los docentes tienen la palabra en los medios didácticos y la interpretación del hecho histórico}

La muestra de los docentes entrevistados se estableció por los grados escolares donde se impartía el tema de la independencia que correspondió al curso de sociales. En España se entrevistaron 9 docentes que se desempeñaban en 2 y 4 de la ESO. Además, a un director de instituto en la ciudad de Alicante. De los 9 docentes, cinco pertenecían a instituciones públicas y cuatro a privadas de la comunidad de Andalucía, en las ciudades de Sevilla, Huelva y Santa María. Todos los profesores tenían formación universitaria más el curso de formación docente de un año, que es obligatorio para ejercer la labor. El director de instituto tenía título de Máster. Los cinco docentes de las públicas tenían sus cargos por oposición y los de las privadas por contrato anual.

Los 42 profesores que se entrevistaron en Colombia, en su totalidad tenían el título de licenciados en sociales, historia o profesiones afines. La profesión docente está regulada en Colombia por el Decreto 2277 de 1979 del Ministerio de Educación, por el cual se adopta el estatuto docente. Sin embargo, se dan grandes cambios a partir de la Ley 115 del 8 de febrero de 1994. En los Artículos 104 y 105 se establece la formación del educador e ingreso por concurso. El Artículo 111 establece la profesionalización, incorporación y ascenso al escalafón; el Artículo 118 estableció el ejercicio de la docencia por otros profesionales con la condición de que en el primer año laboral realizarán una capacitación en pedagogía; y el Artículo 115 estableció la escala de salarios. En los colegios y en la misma

35 De estas 27 públicas 3 corresponden a España y de las 17 privadas 4 corresponden a España. 
universidad se considera que los profesores de sociales son los más críticos en las instituciones educativas.

Como se ha señalado, respecto a los docentes se establece la similitud de una preparación universitaria en ambos países, en los docentes de sociales de los colegios públicos y privados. De igual manera, se establece la similitud de la vinculación de los docentes en los colegios privados, al realizarse por contrato, mientras en los públicos en España se establece la oposición (concurso) y de manera similar también en Colombia y en los dos países existe legislación sobre los mismos.

Cabe anotar, que la primera diferencia, se localiza en la metodología y los medios didácticos que utilizan los profesores para desarrollar sus clases en el proceso de enseñanza-aprendizaje, con el tema de la independencia americana. Si relacionamos por país, en general, en España encontramos que los estudiantes manifestaron haber recibido este tema por explicación del profesor. En Colombia es notoria la diferencia entre los establecimientos escolares públicos y privados ya que es mediada por el sitio donde se haya impartido el tema. Por ejemplo, el Colegio de Boyacá, localizado en la capital del Departamento de Boyacá, se utilizan diferentes estrategias didácticas que se corroboran con las aplicadas por los estudiantes universitarios que realizan sus prácticas docentes en la institución. Similar situación se presentó en el colegio público Promoción Social de Fusagasugá. Pero si hay algo que subrayar o destacar de lo más significativo de los colegios públicos en Colombia, es el hecho que el lugar de ubicación del colegio (capital de provincia ${ }^{36}$, mayor desarrollo económico) incide en la utilización de un mayor número y diferentes medios educativos, por parte del maestro. Estos medios los agrupamos en: videos, películas, hasta la consulta por internet y lo más generalizado en medios que fortalecen la didáctica establecida, en esta enseñanza por parte de los profesores, se ubica en textos, manuales (del profesor) y las guías que ellos elaboran. Los colegios privados tienen diferentes categorías: Algunos consideran que la clase de sociales no es relevante si la comparamos con la de matemáticas y sin embargo, se utiliza el texto y otros medios educativos. Otros privados, consideran relevante la clase de sociales pero no tienen mayores medios educativos. Así las cosas, podemos aproximarnos a comentar, en medio de la diferencia, que los colegios públicos de Colombia manejan una variada gama de metodologías con procesos diferenciados en los recursos utilizados por los docentes y estudiantes. Dentro de estos se incluyen los mapas conceptuales, talleres, debates, lecturas, trabajos elaborados por los estudiantes y por supuesto, el método tradicional de la clase magistral por parte del docente. Asimismo, en los medios didácticos que se localiza en estos colegios públicos predominan: carteleras, fotocopias, internet, consultas, elaboración de mapas y en algunos pocos los videos. En los colegios privados además

36 Provincia en Colombia es lo equivalente a Comunidad en la división geopolítica administrativa. 
utilizan el texto escolar, documentales, talleres, debates, trabajos elaborados y películas. En definitiva, las metodologías más representativas encontradas están ligadas a procesos desarrollados en el aula de clase y estos se orientan hacia unos conocimientos básicos que se deben cumplir para las pruebas de los ECAES (Exámenes de Estado de Calidad de la Educación Superior, establecidas por el Ministerio de Educación Nacional para medir competencias). Se establecía que a través de este tema se iba a desarrollar identidad nacional y competencias ciudadanas, sin embargo, esto solo se encontró en pocos colegios de los encuestados. Por otra parte, el proyecto "Historia Hoy" propuesto por el Ministerio de Educación Nacional, que considerábamos de alto impacto en las instituciones escolares, se localizó que el material suministrado en los "maletines del Bicentenario" solo permitió en escasos colegios, de la muestra, la inclusión de las y los estudiantes en procesos de investigación histórica a través de propuestas y proyectos que generaran interés y trabajo participativo entre los docentes de Ciencias Sociales y los estudiantes en el marco de la enseñanzaaprendizaje de la historia independentista.

Unido a lo anterior, es necesario destacar en este apartado de la diferencia, que la hipótesis 4, con la que iniciamos la investigación, referente al hecho de considerar que "el texto escolar era el medio más relevante que utilizaba el docente en el proceso de enseñanza, en la clase de sociales, y por ende lo considerábamos básico en la enseñanza del tema de la independencia". Enfatizamos, teniendo en cuenta que el texto estaba sustentado por la legislación del país, seguía las orientaciones curriculares del Ministerio de Educación Nacional y el docente orientaba el plan de estudios y el proceso de enseñanza-aprendizaje desde los contenidos que se indicaban en el texto ${ }^{37}$.

Es así, que nos parecía obvio que el tema de la independencia americana vehiculara los imaginarios que se presentaban en el texto. Sin embargo, nos encontramos con situaciones diferentes. La primera, es el hecho de que en España, el texto escolar en la comunidad de Andalucía es gratuito para los colegios públicos y en los privados se compra. La utilización del mismo, era evidente junto con guías que acompañan el texto del docente, que ya vienen elaboradas. Además, puede decirse que la utilización de los medios didácticos era diversa aunque reiteramos con gran influencia la presencia del texto y manual escolar. Es relevante indicar que la legislación española establece las enseñanzas mínimas que se deben impartir en las instituciones escolares. Es así, como sobre estas se elaboran los textos escolares que son utilizados por los docentes. Según, un estudio del historiador Enrique Javier Díez ${ }^{38}$, el texto escolar es utilizado en un $90 \%$ por los estudiantes y profesores en España. Obvio es decir, que el conocimiento de la independencia americana, por parte del docente, era claro en

37 Esta hipótesis la teníamos del anterior estudio sobre textos escolares.

38 Enrique Javier Díez Gutiérrez. “Análisis de los textos escolares de historia. Estudio de caso sobre la posguerra civil española”, Revista Historia de la Educación Latinoamericana. № 16, enero -junio (2011), 90. 
las generalidades del mismo. En definitiva, en España cuando se imparte el tema de la independencia americana, el cual es opcional, se sustenta en el texto escolar fundamentalmente dentro de la clase que "explica" 39 el profesor.

Por otra parte, en Colombia, los colegios públicos, presentan una baja utilización del texto escolar de sociales. El docente utiliza fundamentalmente guías que él elabora y las fotocopias para entregarlas a los estudiantes. Asimismo, los profesores utilizan diferentes medios didácticos incluyendo las consultas en internet en lo referente al proceso de enseñanza-aprendizaje en la clase de sociales. Es conocido que en Colombia no son gratuitos los textos escolares. Por el contrario, los textos escolares de los más utilizados, en el año 2011, de la Editorial Santillana, tenían un valor promedio de 30 dólares. Precio fuera del alcance de las familias que tienen sus hijos en los colegios públicos.

La segunda diferencia es la relacionada con los medios educativos y la biblioteca escolar. En España, los docentes de cada materia tienen su "salón de profesores" con una pequeña biblioteca específica en este lugar que les sirve para preparar las clases y actividades propias del área de conocimiento. Además, se localiza una Biblioteca escolar. Nosotros visitamos el aula de sociales de los profesores donde se tenía una biblioteca con textos escolares localizándose de cada ejemplar un mínimo de 3 textos. Por el contrario, los colegios públicos de Colombia, utilizan el mismo salón de reuniones todos los docentes de las diferentes áreas. No se tiene biblioteca en estos sitios, solo la central del colegio. Esta biblioteca escolar de los colegios públicos, cuenta con muy pocos libros y que generalmente son donaciones realizadas por las editoriales. Respecto a los Bibliobancos ${ }^{40}$ escolares en las instituciones públicas colombianas, son deficientes en el contenido de libros de sociales, encontrando textos incluso de los años 1970 y 1980. Con relación a la publicación que editó el Ministerio de Educación Nacional, con motivo de la celebración de la Independencia, en colección de 11 libros que ya hemos indicado y que se ha denominado "El maletín del Bicentenario", debemos señalar que no los evidenciamos en las bibliotecas escolares de las instituciones visitadas. En algunos casos, se encontraban en las rectorías y en un lugar la localizamos en la alcaldía municipal. Es decir, los estudiantes tuvieron poco acceso a este material en el año 2011. Ante esta situación, ciertamente, debemos destacar las formas recursivas de los docentes de los colegios públicos para explicar el tema de la independencia que incluyen dramatizados sobre este hecho histórico. Por el contrario, la similitud se ubica en la compra de los textos por parte de los estudiantes en los colegios privados de España y de Colombia.

La tercera diferencia, entre España y Colombia referente al tema que nos ocupa, es la intensidad horaria al tema de la independencia dentro del plan de

39 Término que utilizaron los estudiantes españoles en su gran mayoría para identificar el cómo aprendió el tema de la independencia americana.

40 En el caso de Colombia desde 1870, se propugna por el Bibliobanco para las instituciones escolares del Estado sin que se logré llevar a la práctica esta medida. 
estudios de cada curso. En España, tanto en los colegios públicos como privados en 2 y 4 de la ESO se demostró que la enseñanza del tema de la independencia americana, era opcional por parte del docente. En 4 de la ESO sí era evidente la enseñanza pero con una dedicación no mayor a dos horas al tema específico de la independencia americana. En Colombia, por el contrario la enseñanza del contenido de la independencia es obligatoria ${ }^{41}$. Este tema, se inicia en el 4 grado de primaria relacionado a la Nueva Granada; en el 5 grado se profundiza y en 7 y 8 este tópico se amplía a toda América. De la muestra total de instituciones seleccionadas, se pudo determinar que estas dedicaron para la enseñanza del tema de independencia el tiempo correspondiente dentro de un período académico (bimestre), utilizando semanalmente dos horas para el aprendizaje de los contenidos. En las instituciones seleccionadas se presentó de forma general la tendencia de la enseñanza de las Ciencias Sociales de forma disciplinar o por áreas separadas (Historia, Geografía, Democracia). De forma complementaria para la enseñanza-aprendizaje, sobre el tema en concreto de la independencia, las instituciones realizaron diferentes eventos y actividades conmemorativas del bicentenario durante el transcurso del 2010.

\section{El imaginario de la independencia americana. Entre la pérdida y la libertad}

El concepto de independencia en los estudiantes de España y Colombia presentó diferencias notables que se marcaron más por el lugar, tipo de colegio, grado escolar y género, como categorías de análisis de variables independientes y dependientes. El análisis de las respuestas fue cualitativo partiendo del mapa conceptual de las cuatro hipótesis. Hay que decir que no partimos de un concepto rígido sobre la independencia americana. Solo nos interesaba analizar desde el análisis de contenido: las palabras que más utilizaban para conceptuarla; causas y consecuencias de la independencia; identificación de los líderes americanos; y si tenían claridad en el espacio temporal. Con relación a las hipótesis se partió de dos por similitud y dos diferenciales.

La primera hipótesis (similitud), como hemos indicado, referente a los lugares del estudio, que considerábamos presentaba un mayor acercamiento cultural y educativo al tema de la independencia americana. Nos encontramos, precisamente que no existía tal similitud por países. Por el contrario, la primera diferencia es la referente al hecho que los estudiantes españoles de los 7 colegios seleccionados (3 públicos y 4 privados), de Sevilla, Huelva, Puerto de Santa María, de la comunidad autónoma de Andalucía, presentaron que solo en 5 colegios habían recibido la enseñanza del tema de la independencia americana, en la institución educativa, teniendo en cuenta, que esta materia es opcional en

41 El tema de la independencia de la Nueva Granada, solo se ve en primaria en la unidad historia de Colombia, la clase de sociales tiene una intensidad horaria de cuatros hora semanales y aproximadamente el tema de la independencia se le dedica un mes en cuarto grado y un mes en quinto grado. Por el contrario, en la secundaria en 7 y 8 dura una semana cada eje temático. 
la enseñanza de sociales. Por lo tanto, de partida localizamos dos colegios que no habían visto el contenido de la independencia y por lo tanto su imaginario dependía del conocimiento por cultura general que tenían sobre el mismo. Además, nos sorprendió el hecho, desde la mirada americana, que el tema no fuera obligatorio en su enseñanza en el plan de estudios. Por el contrario, como hemos indicado, en Colombia es un eje obligatorio y con un número considerable de horas en $4^{\circ}$ y $5^{\circ}$ de primaria (independencia de Nueva Granada) y menor en $7^{\circ}$ y $8^{\circ}$ que se dedica al tema de la independencia americana. En este contexto debemos indicar que con la celebración del hecho histórico, en el 2010, se inicia la ruta del Bicentenario por parte del Ministerio de Educación Nacional con gran impacto en las 200 preguntas que se realizaron en docentes y estudiantes.

En la que denominamos la tercera hipótesis (similitud) se afirmó, que en los dos países se había dado visibilidad al hecho histórico de la independencia americana. Por las razones ya expuestas, se encontró que en España, en las instituciones escolares donde se realizó la encuesta, no existió ninguna actividad que conociéramos que permitiera visibilizar "la celebración de este hecho histórico" y sobre las cuales corrió bastante tinta en estudios de investigadores de los dos países. Lo que nos lleva a concluir, solo para la muestra de estudio, que no se permeo desde la universidad y las academias de historia a la institución escolar en este tema de la independencia americana ${ }^{42}$.

Por el contrario, en Colombia, el año 2010 fue de celebración de la independencia americana, con actividades que se realizaron en instituciones escolares y en especial presentaron gran impacto del hecho los medios de comunicación, lo cual se evidenció en la variación de las respuestas respecto a la inclusión de términos como paz y ciudadanía. A su vez, predominaron en las contestaciones los imaginarios sustentados en las anécdotas.

La segunda hipótesis (diferencia), se estableció indicando que los estudiantes presentaban diferentes concepciones sobre el tema de la independencia según: país, lugar, institución, grado y género. En este caso, como hemos indicado, realizamos un análisis de contenido de las respuestas. Las preguntas fueron: ¿Qué significa para usted la independencia americana?, ¿Cuáles fueron las causas de esta independencia?, ¿Cuáles sus consecuencias?, ¿Cuáles fueron los líderes de la independencia americana?

En el caso español, respecto a la primera pregunta se identificaron tres tipos de respuesta: una económica, una ideológica y una tercera que denominamos afectiva.

Respecto a la primera respuesta, que hemos señalado como "económica", se encontró que los estudiantes de los 5 colegios ya habían visto el tema, se localizó que en un $80 \%$ de las respuestas la independencia americana, se asociaba con lo económico, exactamente con la palabra "pérdida" que se utilizó

42 En el año 2008, se organizó en cada país una comisión encargada de tal celebración a la que se integró España con motivo de su independencia de Francia en el año 1808. 
para "pérdida de recursos" y "pérdida de los territorios españoles en América". Veamos algunas respuestas más generalizadas de los estudiantes de 2 de la ESO: "Pérdida de Colonias Españolas en América para pasar a ser independientes (hombre, 15 años)"; "La independencia española para mí significa la pérdida de numerosos territorios así como riquezas y recursos naturales, así mismo hizo que España fuera más conocida". (hombre, 16 años). "significa que España pierde su poder económico, político y social en América el cual había tenido por más de trescientos años. (hombre, 16 años)" 43 . "La pérdida de territorios españoles causado por la malísima gestión por parte del gobierno español de entonces (hombre, 17 años)". "pues que España perdió su imperio Colonial totalmente en 1898 con la pérdida de Cuba y Puerto Rico (en América). Y esto produjo una pérdida brutal de ingresos económicos pues tenían estos territorios (hombre, 17 años)", "Pérdida de capital económico, pérdida de vidas humanas. También sirvió para ver la realidad del ejército Español (hombre, 17 años)". "para España fue un duro golpe perder su Imperio, hecho conocido como desastre del 98. La población perdió la confianza en el ejército pues por culpa de la prensa se hizo creer que la guerra contra Norteamérica iba a ser fácil. Aunque políticamente no cambió nada se dio una explosión intelectual, conocida como generación del 98 (Unamuno, Azorín...). Además supuso un gran auge económico en España debido a que se trajo mucho dinero de allí, se crearon bancos como el banco Hispanoamericano ${ }^{44}$ (hombre, 17 años), "La pérdida del comercio y de recursos y la formación de un nuevo Estado, el comienzo del desmoronamiento del Imperio español (hombre, 18 años)" ${ }^{\prime 4}$. Las consecuencias son pues que yo estoy como estoy" (hombre, 15 años); "La reducción de los mercados creando déficits y que los españoles teníamos una gran cantidad de cultivos con los que enriquecíamos la economía y los perdimos" (hombre, 15 años). Un descenso en la riqueza del país tanto económico como político, ya que España perdió poder al independizarse las colonias. Para las colonias fue una malísima inversión, ya que desde entonces están en un estado de pobreza. (hombre, 15 años). De otro lado, generó una interrupción en el suministro de oro a España (aunque muchos negocios en el siglo XIX se trasladaron a nuestro país procedentes del Caribe). (hombre 17 años); "La desmembración de América del sur y las islas del Caribe. En numerosos países ya con sus propias leyes supuso un progreso, sin embargo, nunca ha llegado a ser primera potencia. De otro lado, generó una interrupción en el suministro de oro a España (aunque muchos negocios en el siglo XIX se trasladaron a nuestro país procedentes del Caribe).

Ente las respuestas de tipo ideológico localizamos entre otras: “Significó un duro golpe ideológico en el pueblo Español, ya que este hecho hizo que nos diéramos cuenta de que nuestro poder en el mundo no era el mismo que antes y

43 Colegio Guadalete (privado) - Puerto de Santa María, curso: $4^{\circ}$ eso, 2011.

44 Creado en el siglo XX.

45 Colegio Entrepinos - Huelva, curso: $2^{\circ}$ ESO, 2011. 
que ahora solo éramos una potencia de segundo orden e incluso de tercer orden. Por otra parte supuso un cierto beneficio económico, ya que numerosas empresas y personas importantes de América se dirigieron a España. Para las Colonias significó conseguir la autonomía que ellos deseaban aunque fue una autonomía "ficticia" porque seguían dependiendo económicamente de Estados Unidos (hombre, 17 años)"; La creación de múltiples repúblicas que causaron separación entre los sudamericanos y múltiples guerras civiles, también en algunos países se hicieron en el poder dictadores" (hombre, 15 años). Y por último se produjo una creciente opinión negativa y falsa sobre España impulsada por los Estados Unidos (hombre, 17 años) ${ }^{46}$.

Igualmente existen respuestas afectivas como la de este estudiante: "Significó un golpe en mi corazón, porque me dolió mucho lo de Cuba y Filipinas (hombre, 15 años). La separación de nuestras Colonias en América y fin total del imperio Español, pese a la presión de pertenecer a otro estado, los países sudamericanos estaban más unidos cuando pertenecían a España que ahora. (hombre, 15 años). "Un acto de libertad por parte de los nativos americanos que a pesar de fluir por sus venas sangre española también, no se sentían Españoles, lo que ha llevado también a un engaño generalizado de que España ha hecho bastante mal a los nativos a lo largo de la historia cuando no es cierto (hombre, 17 años)" ${ }^{\prime 7}$.

Por su parte, en las niñas localizamos a una venezolana que contestó: "pues que mi país se independizó (Venezuela) (mujer, 14 años)". Otras indicaron: "la independencia de América Colonial española significa para mí cuando América se hizo un continente independiente, que valía por el mismo (mujer, 13 años)"; "que los países de América se separaron porque no estaban de acuerdo con algo (mujer, 13 años)"; "Que América del sur, que es de habla española, se independizó de América del Norte. (Mujer, 13 años)"

Los 3 colegios que no habían visto el tema indicaron: "yo no he visto ese tema" (respuesta generalizada. Otras: "para mí la independencia de las colonias Americanas no significa nada, ya que cuando nací, ya estaba así la cosa por lo que no me ha afectado nada. (hombre, 15 años)."creo que es la independencia de Francia"'(niña 14 años).

En definitiva, se establece que en las respuestas no se da diferencia entre público y privado en cambio, sí por género. Los niños aducían en general al problema económico, mientras que las niñas repiten la palabra independencia con algún adjetivo de libertad. Otras respuestas, están fuera del contexto histórico. Estas últimas, se localizan fundamentalmente en los colegios que no recibieron el tema en el aula de clase.

En Colombia, a esta primera pregunta sobre la independencia se encuentra que es más elaborada en la medida que se pasa de la primaria a la secundaria. Las

46 Colegio Entrepinos - Huelva, curso: $4^{\circ}$ ESO, 2011

47 Colegio Entrepinos - Huelva, curso: $4^{\circ}$ ESO, 2011.

48 Encuestas aplicadas en España, en el colegio público "Gustavo Adolfo Bécquer, Sevilla, en el año 2011. Curso: $2^{\circ}$ ESO. 
respuestas siguiendo la catalogación de las preguntas en los colegios españoles se localiza, en el primer caso referente a lo económico, que como puede suponerse no existe la palabra pérdida. Por el contrario, se indica "empezamos a manejar nuestros recursos": "nos dimos nuestras propias leyes", fuimos libres, "salir a marchar por amor y paz". Nos pareció curioso, que no se diera respuestas como los españoles nos "robaron el oro"que si las habíamos localizado en un estudio del año $1992^{49}$.

En cuanto al aspecto ideológico, predominan las palabras libertad, liberación del yugo español, se acabó la esclavitud, Es así, que las palabras las catalogamos por niveles en los cursos: en la primaria se asocia la palabra independencia americana con "Libertad de los españoles y fin de la esclavitud" Libertad. Salir de la esclavitud (niña 5 grado, 11 años), Lucha de criollos y chapetones. Muerte y guerra (5 grado, 11 años niño), en la secundaria se presentaron respuestas más elaboradas con argumentos. Se incluyen las palabras: democracia, opresión, elaboración de leyes y constituciones, aunque se coincide con las palabras libertad, liberación, yugo, esclavitud referenciando a la metrópoli española. Algunas de las frases comunes en secundaria que localizamos fueron: Lo que significó con el Pantano de Vargas. Dejar de depender de alguien, ser autónomo (grado 9, niña). "Acto en el pasado que marcó el futuro de todos" (niño 16 años, grado 10). Cuando fuimos liberados de los españoles de su mandato e inicia una democracia y un mandato por el pueblo colombiano. (10 grado, niña)

Destacamos al Colegio del Pantano Vargas (público) con frases como estas que fueron las más recurrentes en las respuestas: Hacer cosas por el colegio como izada de bandera. (niña 5 grado, 11 años), Proceso para la libertad, igualdad, derechos para todos (niña 6 grado, 12 años). Hacer valer nuestros derechos frente a España. (Liberación del país $8^{\circ}$ grado, niño de 14 años); La liberación del yugo español, no seguir dependiendo de ellos sino valernos por sí mismos, buscar la libertad e igualdad para todos ( $9^{\circ}$ grado niño 15 años). No se localizó diferencia por tipo de colegio ni por sexo.

En la segunda pregunta (sobre las causas de la independencia americana), se encontró en los 5 colegios españoles que habían visto el tema, respuestas generalizadas como: "por la influencia de Francia, la influencia de Estados Unidos, que los españoles no sabían gobernar". Desde esta perspectiva, se establece una gran diferencia porque en Colombia a la segunda pregunta se indica como causa central: "El florero, la esclavitud, los impuestos, los Derechos del Hombre".

A la tercera pregunta (las consecuencias de la independencia americana), la palabra más utilizada por los niños y niñas españoles fue: "que perdimos"; ganamos que los criollos trajeron su dinero y fundaron bancos. Por su parte, los niños y niñas colombianas manifestaron que las consecuencias se centraron

49 Diana Soto Arango. "El encuentro de dos mundos: enseñanza y textos escolares en Colombia", en Revista Ciencias de la Educación de España, $\mathrm{n}^{\circ}$ 155, julio-septiembre de (1993): 435-446. 
en "obtener la libertad", hacer leyes, darnos nuestro gobierno. No se estableció mayor diferencia por tipo de institución y género.

En la cuarta pregunta (sobre los líderes de la independencia americana), indicaron en los colegios españoles, indiscriminadamente los nombres de Simón Bolívar, San Martín y Jorge Washington. Los que no habían visto el tema confunden de época a los personajes: De esta manera ubican en la independencia a personajes como Colón, Pizarro y a Hugo Chávez. A esta pregunta en los colegios de Colombia en un 90\%, indican a Simón Bolívar. Se debe tener en cuenta que en Colombia en la mayoría de las plazas principales (plazas mayores) se les denomina, Plaza de Simón Bolívar. Las respuestas más generalizadas en todos los grados se asoció a Bolívar con las batallas y el ejército. Entre otras podemos indicar: Bolívar y su ejército que da libertad.

En la quinta pregunta (respecto a los medios por el cual recibieron la información de la independencia americana), en su mayoría, de los 5 colegios españoles que habían visto el tema, indicaron que era por explicación del profesor, libro, guías e internet. Es curioso, pero ninguno relacionó a los medios de comunicación como radio, prensa o televisión. En este apartado, no se localizó diferencia entre las respuestas de los niños y niñas, solo con alguna variación de estas últimas de ser más explícitas en las respuestas. En Colombia, fue claro que todos habían recibido el tema en el aula de clase y las encuestas realizadas en octubre de 2010 y mayo de 2011, se encuentran permeadas por los medios de comunicación y las celebraciones realizadas. Es notoria la gran influencia de la televisión, en especial se localiza un gran número de respuestas alusivas a la telenovela de La Pola, preferente en las respuestas de las niñas.

La cuarta hipótesis (diferencia) es que existía diferencia en los procesos de enseñanza y utilización de medios educativos, por parte de los profesores, en los dos países y por tipo de institución. Esta hipótesis nos llevó a conclusiones diferentes. El mapa conceptual se había estructurado para mostrar diferencias y los resultados de las entrevistas demostraron que existía diferencia en los procesos de enseñanza. Sin embargo, se evidenció que los docentes colombianos eran más recursivos, utilizando medios del entorno y del aula, precisamente por la falta de materiales educativos, especialmente en los colegios públicos. En estos se utiliza el dramatizado, talleres y en los colegios españoles se constató que están más ajustados al texto escolar. 


\section{CONCLUSIÓN}

Respecto al imaginario de la independencia americana es diferente por país, colegio, y género, donde el profesor y el texto tienen la palabra. En las instituciones españolas y colombianas el docente es influido por los medios de comunicación. Se evidencian, concepciones diferenciadas con vocabulario que conllevan a diferentes imaginarios desde dos orillas sin posibilidad de acercamiento conceptual sobre este tema histórico. Por otra parte, los estudios de los investigadores universitarios, no permean el aula de clase de las instituciones escolares, excepto, a través del texto escolar cuando ellos están presentes en la elaboración de los mismos. Esta es una asignatura pendiente en relación a las estrategias para que las investigaciones realizadas, desde las instituciones universitarias, establezcan esa relación con la sociedad, y se asuma el papel de interlocutor activo en el diálogo social, en busca de nuevos abordajes que incluyan los valores humanos de solidaridad y de tolerancia que en el caso colombiano, desde el contexto histórico actual, permitan en las comunidades educativas escolares los cambios en estructuras mentales, que desde esa pregunta planteó la presente investigación sobre los imaginarios en la independencia americana nos lleve a otros vocabularios, para entender el pasado histórico revindicando, reiteramos los valores de la democracia, la inclusión y la libertad.

Asimismo, se demuestra, para el caso colombiano, que las estrategias de calidad en la educación que desarrolla el Ministerio de Educación Nacional no permean los colegios públicos de los pueblos como es el caso del texto escolar en los Bibliobancos. Sin embargo, los planes de estudio se rigen por lo emanado por este Ministerio.

Nuestro aporte en esta reflexión final, se centra en evidenciar que los procesos de enseñanza-aprendizaje, desde el aula escolar, están marcados de manera diferencial en los aspectos conceptuales en este tema de la independencia americana, y son mediados por la concepción del educador y los medios de comunicación esto último para el caso de Colombia. De ahí, la relevancia de realizar estudios sobre cómo influyen los medios de comunicación en la institución educativa, en las prácticas de una cultura política y en los imaginarios sociales de tolerancia y convivencia enmarcados desde las identidades institucionales, regionales y nacionales.

Finalmente, hay que decir, que el tema de la independencia americana presentó en Colombia posiciones ideológicas y políticas diferentes entre la posición del gobierno y la de los maestros que no siempre coinciden. Pero, en definitiva, lo que se evidencia, es que los imaginarios sobre la independencia americana difieren por país (España y Colombia) por tipo de colegio (público y privado) y por género. $Y$, en efecto, si se piensa que los docentes tienen la palabra, junto con los medios de comunicación, es allí donde está un largo camino por 
recorrer y una gran responsabilidad de las instituciones formadoras de docentes en las nuevas prácticas y cultura política de acercamiento de naciones y valores culturales para nuestras naciones del siglo XXI. Es allí donde se podrá dialogar de identidades regionales, nacionales en esta sociedad del conocimiento del siglo XXI, y dar quizá respuesta a las preguntas del concurso del bicentenario como la realizada por la niña ${ }^{50}$ de 7 grado de ¿Quiénes eran y cómo se formaban los maestros en la época colonial? que nos lleva a parafrasear y concluir con la gran preocupación de ¿Quiénes son y cómo se forman los educadores en Colombia? desde la visión de un nuevo país que se prepara para la paz desde la inclusión y la tolerancia.

\section{FUENTES}

\section{Instituciones Educativas}

Entrevistas en los colegios de España en el mes de marzo del 2010 y febrero del 2011:

Colegio Entrepinos (grado 4 de la ESO)

Colegio Guadalete en el Puerto de Santa María (grado 4 de la ESO)

Colegio Tierra Llana en Huelva (grado 4 de la ESO solo femenino)

Colegio José Santos Gutiérrez El Cocuy octubre de 1991.

Instituto de Educación Superior Gustavo Adolfo Bécquer, Sevilla, Público, (grado 2 de la ESO),

Instituto de Educación Superior Santa Aurelia, Sevilla, Público, (grado 4 de la ESO)

Institución Educativa Escuela Normal Superior y Anexa Socha - Boyacá 07-II-2011

Institución Educativa Técnico Agrícola de Paipa y Anexa 01 - III - 2011

Institución Educativa Técnica Municipal Juan José Rondón y Anexa (Pantano de Vargas - Paipa) 22 - III - 2011

Institución Educativa El Rosario (Paipa) 22 - 03- 2011

Institución Educativa Tomás Vásquez Rodríguez (Paipa) - 12 - 04 - 2011

Institución Educativa Armando Solano (Paipa) - 01 - 03- 2011

Institución Educativa Fray Arturo Ayala (Paipa) - 12 - 04 - 2011

Institución Educativa Juan Bautista María Vianney (Paipa) - 21 - 04 - 2011

Institución Educativa Académica de Paipa 14, 20 y 21 - 06 - 2011

Institución Educativa Tomás Vásquez Rodríguez (Paipa) - 12 - 04 - 2011

\section{Legislación}

Constitución Política de Colombia se publicó en la Gaceta Constitucional Número 127 del día jueves 10 de octubre de 1991.

Decreto 1860 de 1994. Aspectos pedagógicos.

50 La niña Jaritza Duque Marín de 7 grado de Abejorral, Antioquia realizó la 082 pregunta seleccionada en este concurso del Ministerio de Educación Nacional "Bicentenario de la independencia de Colombia, 1810-2010. 
Decreto 1075, mayo de 2015 se expidió el que unifica todas las leyes y decretos en educación en Colombia.

Escuela Normal Superior Nuestra Señora del Rosario Güicán de La Sierra.

Ley 115 General de la Educación del 8 febrero de 1994.

Ministerio de Educación y Ciencia (2007): Boletín Oficial del Estado Español, Real Decreto 1467 de 2 de noviembre, por el cual se estructura el bachillerato y se fijan sus enseñanzas mínimas, número 266, 45381-45477.

Ministerio de Educación y Ciencia de España. "Enseñanza Superior Obligatoria". [en línea]. [España]. http://www.mec.es/educacion/que-estudiar/educacionsecundaria-obligatoria.html. (consultado 30 enero de 2015).

Ministerio de Educación y Ciencia (2007): Boletín Oficial del Estado Español, Real Decreto 1631 de 29 de diciembre, por el cual se establecen las enseñanzas mínimas correspondientes a la Educación Superior Obligatoria, número 5, pp. 667-773.

Plan Decenal de educación, 1995 al 2005, se rigió por la Ley 115 del 8 de febrero 1994.

Resolución 2343 del 5 junio de 1996 (logros curriculares).

\section{REFERENCIAS}

Benedict Anderson. Imagened Communities, Verso, London, 1983.

Casanova, Julián. La historia social y los historiadores. Barcelona: Edt. Crítica. Leer: Todo el libro. Biblioteca.

Díez Gutiérrez, Enrique Javier. “Análisis de los textos escolares de historia. Estudio de caso sobre la posguerra civil española", Revista Historia de la Educación Latinoamericana. $\mathrm{N}^{\circ} 16$, enero -junio (2011), 90.

Fontana, Joseph. La historia de los hombres del siglo XX. Barcelona: Editorial Crítica, 2002.

Fontana, Joseph y otros. Hacia una nueva Historia. Prólogo de Alberto Manuel Prieto Arciniaga. Madrid: Akal Editor, 1976.

Georges. Historia social e ideología de la sociedad. Barcelona: Anagrama, 1976.

Marc Bloch. Historia e historiadores. Madrid: Editorial Akal, 1999.

Paulston, R. "Mapping comparative education after postmodernity", (Comparative Education Review, 43,1999), 438-463.

Paulston, R. Mapping comparative education after postmodernity, (Comparative Education Review, 43,1999), 438-463.

Paulston, R. Imagining comparative education: past, present, future, Compare Review, 30 (2000), 354-359.

Paulston, R. Mapping discourse in comparative education text, Compare Review 23, (1993),106. Se incluyo 4 hipótesis dos desde la diferencia y dos por la similitud.

Rubio Mayoral, Juan Luis y Guadalupe, Trigueros Gordillo "La formación de la conciencia andaluza y el ser andaluz en los manuales escolares", en Ciudadanía e 
identidades en los manuales escolares (1970-2012). (Edt.). Miguel Beas Sevilla España: Diada Editorial, 2013.

Soto Arango, Diana. "La independencia americana en los textos escolares en Colombia", en Ed. Rosa M. Bestani... [et.al.]. - Textos, autores y bibliotecas. 190 años de la Biblioteca Mayor de la UNC. (Córdoba. Universidad Nacional de Córdoba, Argentina. Biblioteca Mayor, 2011.

Soto Arango, Diana. “Ciencias de la educación y pedagogía. Un debate inconcluso en las Facultades de Educación en Colombia" en Revista Ambiente Educação, (Brasil) Revista digital http:/ / www.cidadesp.edu.br/old/revista_educacao/index.html Soto Arango, Diana. Francisco Antonio Zea un criollo Ilustrado. Madrid, Colección Thesauros. (RUDECOLOMBIA, CONUEP, Instituto Colombiano de Cultura Hispánica, Consejo Superior de Investigaciones Científicas, COLCIENCIAS, Ediciones Doce Calles, 2000.

Soto Arango, Diana. "El encuentro de dos mundos: enseñanza y textos escolares en Colombia", en Revista Ciencias de la Educación de España, $\mathrm{n}^{\circ}$ 155, julio-septiembre de (1993): 435-446.

Vovelle, Michelle. Ideologías y mentalidades. Barcelona: Editorial Crítica, 1987.

Soto Arango, Diana Elvira y Bernal Villate, Sandra Liliana y Pacheco Vargas, William y Espinosa, Yules Alejandro y Paternina Soto, Liliana y Perelló, Beatriz. “La enseñanza de la Independencia Americana en Colombia y España 2009-2011". Revista Historia de la Educación Latinoamericana. Vol. 17 No. 25 (2015): 187-212. 